\title{
Synthesis and in vitro/vivo Evaluation of Iodine-123/124 Labelled Hypericin Derivatives
}

\author{
Sang Wook Kim, Jeong Hoon Park, ${ }_{+}^{+,}$Seung Dae Yang, ${ }^{\ddagger *}$ Min Goo Hur, ${ }^{\dagger}$ Chang Woon Choi, ${ }^{\ddagger}$ and Kook Hyun Yu ${ }^{\S, *}$ \\ ${ }^{\dagger}$ Radiation Research Division for Industry \& Eniromnen, Korea Atomic Energ Research Instinte, Jeongeup 580-185. Korea \\ "E-mail: sdyang@kaerire.k. \\ ${ }^{\ddagger}$ Department of Nuclear Medicine, Korea Instittte of Radiological and Medical Sciences, Seoul 139-706, Korea

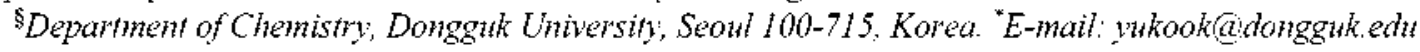 \\ Received June 25, 2008
}

\begin{abstract}
To evaluate the potential of radioiodine labelled hypericin as a malignant glioma inaging agent, L-25l MG, U-373 MG, C6 glioma and fibroblast were treated with a I-123 labelled hypericin derivative and C6 glioma transplanted nude mouse were injected with a I-124 labelled hypericin derivative for a micro PET imaging. 2Iodohypericin was prepared as a reference compound. In this paper, we describe the syntheses of 2iodohypericin and $2-\left[{ }^{123} \mathrm{I} /{ }^{124} \mathrm{I}\right]$ iodohypericin and the results of a corresponding biological evaluation. In all glioma cell lines, 2-[ $\left.{ }^{123} I\right]$ iodohypericin uptake was increased in a tine dependant manner and an accumulation of 2-[ $\left.{ }^{124} \mathrm{I}\right]$ iodohypericin was observed in $\mathrm{C} 6$ glioma bearing nude mouse. These results suggest that radioiodine labelled hypericin can visualize a PKC overexpressed malignant glioma.
\end{abstract}

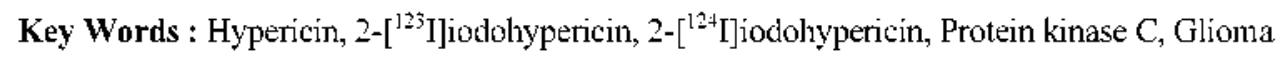

\section{Introduction}

Hypericin (1), a natural polycyclic aromatic dianthraquinone, has mostly been found in plants of the Hypericum genus (St. John's wort). St. John's wort has been considered as a medicinal herb and used in the treatment of a depression as a folk remedies. ${ }^{1}$ Recent studies have found several interesting biological effects of $\mathbf{1}$ for its antiretroviral activity against several types of virus including human immunodeficiency virus (HIV). Clinical trials have been carried out using 1 with HIV-infected patients and positive results have been observed. ${ }^{2-5} 1$ has been known to have a photodynamic therapeutic effect on some cancer types and its photosensitizing effect for photodynamic therapy (PDT) has been intensively explored. ${ }^{6-11}$ One of the interesting investigations concerning 1 is an inhibitory effect on malignant glioma showing an elevated protein kinase C (PKC) activity, ${ }^{11}$ and moreover its enhanced PKC activity strongly correlates with the growth rates of malignant gliomas. ${ }^{12}$ One of the major concerns of this study is to evaluate the possibility of $\mathbf{1}$ as a malignant glioma imaging agent for PET (Positron Emission Tomography) or SPECT (Single Photon Emission Computed Tomography). PKC is a multi functional and ubiquitous enzyme system related with signal transduction pathways. ${ }^{15}$ Recent interests have focused on a PKC expression level in malignant glioma cells because malignant glioma cells show an elevated PKC activity when compared to normal cells. ${ }^{12}$ Other works have shown that PKC activities correlate with the proliferation rate of glioma and increased PKC activities thus reflect the malignancy of tumor cells. ${ }^{1+}$ Other works have demonstrated that manipulations of the PKC system can alter the growth rates of human malignant glioma cell lines in vifro and $\mathbf{1}$ has been demonstrated to

Abbreviations: PET, positron emission tomography; PKC, protein kinase $\mathrm{C}$; HIV, human imumunodeficiency virus; SPECT, single photon emission computed tomography; PDT, photodynaunic therapy have an inhibitory effect on PKC activity. ${ }^{15.16}$ Taken together the previous studied results, radioiodine labelled hypericin could possibly be used as a malignant glioma imaging agent. In this study, 2-iodohypericin (2) was synthesized as a reference compound and a direct labeling of 1 with $\mathrm{I}-123$ or I-124 to give a 2- $\left[{ }^{123} \mathrm{I}\right]$ iodohypericin $\left(\left[{ }^{123} \mathrm{I}\right] 2\right)$ or $2-\left[{ }^{124} \mathrm{I}\right]$ iodohypericin $\left(\left[^{124} \mathrm{I}\right] 2\right)$ was conducted. ${ }^{17.18}$ The biological evaluations of $\left.{ }^{123} \mathrm{I}\right] 2$ were done with malignant glioma cell lines (C6, L-251 MG and L-373 MG) and a fibroblast cell line. Finally, micro PET image of $\left.{ }^{124} \mathbf{I}\right] 2$ was acquired with $\mathrm{C} 6$ transplanted nude mouse.

\section{Results and Discussion}

Hypericin (1) was synthesized as a precursor for a radio iodination and resulted in a relatively good yield of $65 \%$. The irradiation of protohypericin in bright sunlight did not provide a sufticient energy for a photocyclization to produce hypericin while an irradiation with a 200 watt glow lamp for 24 hours produced an acceptable conversion yield of $91 \%$. The reference compound, 2 , was prepared by the reaction of

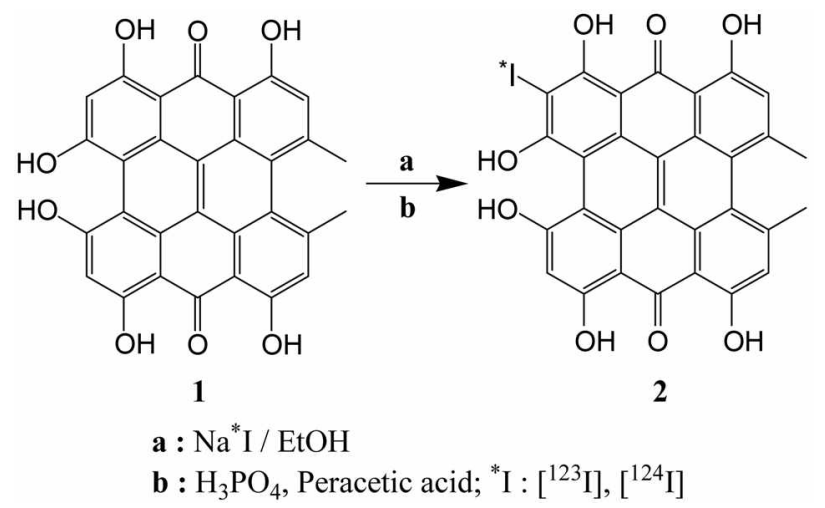

Figure 1. Preparation of 2-Iodohypericin (2), 2-[ $\left.{ }^{123} \mathrm{I}\right]$ iodohypericin $\left(\left[{ }^{13} I\right] 2\right)$ and $2-\left[{ }^{124} I\right]$ iodohypericin $\left(\left[\left[^{134} I\right] 2\right)\right.$. 
Table 1. Cellular Uptake of no carrier added (nca) $\left[{ }^{123} \mathrm{I}\right] 2$ and carrier added $\left(0.5 \mathrm{mg}\right.$ hypericin/mL) $\left[{ }^{123} \mathrm{I}\right] 2$. Results are presented as a percentage of the injected radioactivity dose $(\% \mathrm{D})$ (mean $\pm \mathrm{SD}$ )

\begin{tabular}{lcccrrr}
\hline & $10 \mathrm{~min}$ & $30 \mathrm{~min}$ & $60 \mathrm{~min}$ & \multicolumn{1}{c}{$120 \mathrm{~min}$} & \multicolumn{1}{c}{$240 \mathrm{~min}$} & $360 \mathrm{~min}$ \\
\hline Fibroblast (CA) & $0.55=0.01$ & $0.61 \pm 0.01$ & $0.84 \pm 0.03$ & $0.87=0.07$ & $0.81 \pm 0.02$ & $0.78=0 .(12$ \\
Fibroblast (NCA) & $0.65=0.02$ & $0.70 \pm 0.01$ & $0.94 \pm 0.23$ & $0.98=0.30$ & $0.86 \pm 0.04$ & $0.85=0.03$ \\
C6 (CA) & $0.57=0.05$ & $2.00 \pm 0.05$ & $4.95 \pm 0.43$ & $10.17=0.89$ & $16.19 \pm 1.10$ & $17.42 \pm 1.24$ \\
C6 (NCA) & $0.28=0.04$ & $0.72 \pm 0.06$ & $1.45 \pm 0.15$ & $2.81=0.01$ & $5.31 \pm 0.09$ & $6.72 \pm 0.03$ \\
U-251 MG (CA) & $0.70=0.03$ & $1.79 \pm 0.13$ & $3.19 \pm 0.16$ & $6.42 \pm 0.26$ & $10.06 \pm 0.50$ & $13.97 \pm 0.64$ \\
U-251 MG (NCA) & $0.25=0.03$ & $0.76 \pm 0.08$ & $1.17 \pm 0.04$ & $2.10=0.20$ & $4.08 \pm 0.13$ & $5.19=0.30$ \\
U-373 MG (CA) & $0.88=0.20$ & $1.66 \pm 0.13$ & $2.83 \pm 0.35$ & $7.02 \pm 0.01$ & $12.64 \pm 0.53$ & $18.61 \pm 0.32$ \\
U-373 MG (NCA) & $0.22=0.04$ & $0.64 \pm 0.03$ & $1.42 \pm 0.06$ & $2.19=0.20$ & $3.82 \pm 0.15$ & $5.32=0.35$ \\
\hline
\end{tabular}

hypericin and sodium iodide in the presence of peracetic acid. Although we did not separate the multi-iodinated hypericin, di-iodinated hypericin was found during the LCl MS analysis as well as $\left.2 .{ }^{123} \mathrm{I}\right] 2$ was separated and collected with semi-preparative HPLC prior to a cellular uptake experimental.

The results of a cellular uptake of $\left[{ }^{123} I\right] 2$ are shown in Table 1. The cellular uptake of $\left[{ }^{123} \mathrm{I}\right] 2$ increased in a time dependent manner up to 6 hours for both the carrier added (CA) group and no carrier added ( $\mathrm{XCA}$ ) group.

CA group showed a higher uptake value when compared to those of the $\mathrm{XCA}$ group for C6, U-251 MG and $\mathrm{U}-373$ MG. But, the NCA group showed a higher uptake value for fibroblast cell line. Although these results match the PDT related works concerning an enhanced tumor accumulation after an administration of relatively large amounts of hyperi$\operatorname{cin}(5 \mathrm{mg} / \mathrm{kg})$ well, the exact mechanism and the role of the carrier hypericin in the over cellular uptake process remains unexplained. ${ }^{22}$ From the cellular uptake value of $\left[{ }^{123} \mathrm{I}\right] 2$ on C6, U-251 MG and U-373 MG at $6 \mathrm{~h}(17.425,13.978$ and $18.617 \% \mathrm{D}$ for $\mathrm{CA}$ group $6.728,5.196$ and 5.326 for $\mathrm{NCA}$ group), the affinity of $\left[{ }^{123} \mathrm{I}\right] 2$ on a PKC overexpressed glioma was considered to be strong. This result implies that $\left[{ }^{123} \mathrm{I}\right] 2$ could visualize a malignant glioma. The $\left[{ }^{124} I\right] 2$ was formulated with surfactant according to previously described methods owing to its low solubility. ${ }^{18}$ The coronal views of the PET images of the tumor-bearing mice were obtained at 60 min after an administration of $\left[{ }^{124} \mathrm{I}\right] 2$ as shown in Figure 2. In the PET images at $60 \mathrm{~min},\left[{ }^{124} \mathrm{I}\right] 2$ was selectively accumulated in the C6 glioma of the nude mouse and there was no significant uptake of $\left[{ }^{124} I\right] 2$ in the other organs. There was some uptake of $\left[{ }^{124} \mathrm{I}\right] 2$ in the thyroid which is assumed to be a de-iodination of ${ }^{124} \mathrm{I}^{-}$from $2-\left[{ }^{124} \mathrm{I}\right]$ iodohypericin. This image suggests that $\left[{ }^{12+} \mathrm{I}\right] 2$ could be used as a malignant glioma imaging agent.

It has been known that hypericin can effectively penetrate the blood-brain barrier (BBB) ${ }^{23}$. But, there is a possibility that $\left[{ }^{123} \mathrm{I}^{124} \mathrm{I}\right] 2$ cannot penetrate the BBB due to its relatively large molecular size $(628 \mathrm{kDa})$ and a report that a significant brain uptake of $\left[{ }^{123} \mathrm{I}\right] 2$ has not been observed in a biodistribution study in a normal mouse although $\left[{ }^{123} \mathrm{I}^{124} \mathrm{I}\right] 2$ showed good in vitroin vivo results on a PKC overexpressed malignant glioma in our experiments. It is necessary that a further evaluation of $\left[{ }^{123} \mathrm{I}^{12+} I\right] 2$ be made to ensure whether it can penetrate or not in a real in wivo system. If the problem con-

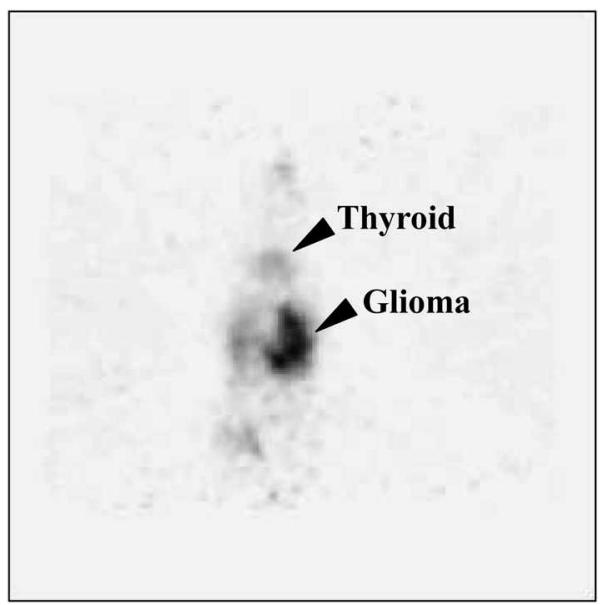

Figure 2. PET image of $\left[{ }^{124} \mathrm{I}\right] 2$ in a $\mathrm{C} 6$ gliona bearing nude mouse. $\left[{ }^{12} \mathrm{I}\right] 2$ was selectively localized in the right back glioma of a mouse and also accumulated in the thyroid. PET image was obtained at 60 min postinjection.

ceming the $\mathrm{BBB}$ penetration occurs owing to the large size of $\left[{ }^{123} \mathrm{I}^{124} \mathrm{I}\right] 2$, the introduction of radio nuclide with a small size like ${ }^{18} \mathrm{~F}$ and ${ }^{11} \mathrm{C}$ should be considered and evaluated.

\section{Experimental Section}

Chemistry and Radiochemistry. Hypericin (1) and iodinated hypericin were prepared and purified with silica and Sephadex LH-20 column chromatography by previously published methods with some modifications. 17, 19:20 $^{2}$

A similar method to a non-radioactive iodinated hypericin preparation was applied for the preparation of the radioiodinated hypericin. ${ }^{17}$ The labeling reaction was monitored by radio-TLC and the labeling yield of $\left[{ }^{123} \mathbf{I}\right] 2$ was $60-65 \%$. Purification of $\left[{ }^{123} \mathrm{I}\right] 2$ was performed on a semi-preparative high performance liquid chromatography (HPLC) system consisting of the following components: a Rheodyne 7010 injector equipped with a $2 \mathrm{~mL}$ sample loop, a Young-Lin M930 HPLC pump (Young-Lin, Korea) and a Young-Lin M720 UV detector (wavelength: $590 \mathrm{~nm}$ ) in series with a Raytest GABI radioactivity detector (Raytest, Germany). A Waters X-terra radial R Prep RP18 column $(300 \times 7.8 \mathrm{~mm}$, $10 \mathrm{~mm}$ ) (Waters Corporation, Milford, USA) was eluted isocratically with a mixture of $50 \mathrm{mM}$ aqueous ammonium acetate and absolute ethanol $30 / 70(\mathrm{v} / \mathrm{v})$ at a flow rate of 2 $\mathrm{mL} / \mathrm{min} .\left[{ }^{123} \mathrm{I}\right] 2$ was eluted with a retention time of about 21 
min. The product fraction $(6 \mathrm{~mL})$ was concentrated with a nitrogen stream to about $0.5 \mathrm{~mL}$ prior to use.

\section{Binding Studies.}

The cell culture: Two human glioblastoma cell lines, $\mathrm{U}$ $251 \mathrm{MG}$ and U-373 MG and one rat glioblastoma cell line. C6 were utilized in this study. Fibroblast from human skin was used instead of a low-passage malignant glioma cell. Cells were grown in Dulbecco's Modified Essential Medium (DMEM, Gibco BRL Products, Gaithersburg. MD) with 1.5 g/L sodium bicarbonate supplemented with $10 \%$ fetal bovine serum (FBS) and $100 \mathrm{mg} / \mathrm{mL}$ of penicillin-streptomycin (Gibco). Cells were maintained as monolayers in a humidified $5 \% \mathrm{CO}_{2}$ atmosphere, normally in T-75 flasks (Falcon. Becton Dickinson, Lincoln Park. NJ). The cells were trypsinated in the $\mathrm{T}-75$ flasks at a $80-90 \%$ confluence using $0.05 \%$ trypsin $/ 0.02 \%$ EDTA and were then suspended in DMEM with $10 \%$ FBS to the desired density, normally $1.2 \times$ $10^{6}$ cells $/ \mathrm{mL}$. Cell growth status and viability was monitored by an inverted phase contrast microscopy. Trypan blue exclusion was also used to assess their viability.

$2-\left[{ }^{123} I\right]$ iodohypericin uptake: The four cell lines were seeded at $5 \times 10^{5}$ in 6 well plates at $3 \mathrm{~mL}$ per well and incubated at $37^{\circ} \mathrm{C}$ in $5 \%$ carbon dioxide for $18 \mathrm{~h}$ for an adherence and growth. To each well in triplicate $100 \mu \mathrm{L}$ of $\left[{ }^{123} \mathrm{I}\right] 2(370 \mathrm{kBq})$ was added, and the well plates were incubated for $24 \mathrm{~h}$. The medium was removed at $10 \mathrm{~min}, 30$ $\min , 1,2,4$ and $6 \mathrm{~h}$. Each well was then trypsinized, and washed twice with PBS. The cell pellets were counted by a well-type gamma counter 1480 WIZARD (WALLAC, Finland). A cellular uptake study was carried out for both $\mathrm{NCA}\left[{ }^{123} \mathrm{I}\right] 2$ and $\mathrm{CA}\left[{ }^{123} \mathrm{I}\right] 2(0.5 \mu \mathrm{g}$ hypericin $/ \mathrm{mL})$ to investigate the influence of the hypericin mass on a cellular uptake of $\left[{ }^{123} \mathbf{I}\right] 2$.

Tumor Model. Balb/C nude mice (7 weeks, $22 \mathrm{~g}$ ) were used to prepare a tumor-bearing model. Mice were kept in cages with standardized conditions of light, asepsis and free access to water and food. Approximately $1 \times 10^{6} \mathrm{C} 6$ glioma cells were inoculated subcutaneously on the back of the mice. Experiments were performed 7-14 days after an inoculation when a tumor diameter of about $0.7-1.0 \mathrm{~cm}$ was observed. All aspects of the animal experiment and husbandry were carried out in compliance with National regulations.

PET Studies. After $30 \mathrm{~min}$ of intravenous injection of $\left[{ }^{12+} \mathrm{I}\right] 2(3 \mathrm{MBq} / 200 \mu \mathrm{L})$, mice were sacrificed with a lethal dose of diethyl ether. Using a dedicated PET scanner (ECAT EXACT HR+ scanner, SIEMENS/CTIMI, Knoxville, Tenn), an acquisition was performed in a 2-dimensional mode. Using a germanium-68 source, transmission images were obtained for $5 \mathrm{~min}$ to correct photon attenuation. After the transmission scan, emission images were obtained for 15 min, and the acquisition data were reconstructed using an iterative reconstruction and segmented attenuation. The total acquisition time was $20 \mathrm{~min}$.

\section{Conclusion}

In conclusion, the limited structural changes of hypericin showed a negligible effect on a glioma uptake in vivo and in vitro. This phenomenon has also been proved in other applications of hypericin derivatives in a biodistribution study ${ }^{18}$ and in PDT ${ }^{24: 25}\left[{ }^{123} \mathrm{I}\right] 2$ showed a good possibility as a new radiopharmaceutical for PKC overexpressed malignant glioma cell lines in the presence of hypericin as well as the absence of hypericin. $\left[{ }^{124} \mathrm{I}\right] 2$ produced a good micro PET image with a PKC overexpressed malignant glioma xenografted mouse.

Acknowledgments. This work was supported by Nuclear R\&D Program from the Ministry of Science \& Technology and the Dongguk University Research Fund.

\section{References}

1. Gruszeck-Kowalik, E.; Zalkow, L. H. Org. Prep. Proc. Int. 2000, 32,57 .

2. Muruelo, D.; Lavie, G.; Lavie, D. Proc. Natl. Sci. USA 1988, 85, 5230 .

3. Lavie, G.; Valentine, F.; Levin, B.; Mazur, Y.; Gallo, G.; Lavie, D.; Weiner, D.; Muruelo, D. Proc. Natl. Acad. Sct. 1989, 86, 5963.

4. Lavie, G.; Mazur, Y.; Valentine, F.; Lavie, D.; Levin, B.; ltta, Y.; Muruelo, D. Therapies and Vaccines of the Annats of the New York Academ of Sciences $1995,616,556$.

5. Kraus, G A.; Pratt, D.; Tossberg, J.; Carpenter, S. Biochem. Biophns. Res. Commm 1990, 172, 149.

6. Lavie, G.; Kaplinsky, C.; Toren, A.; Aizman, I.; Meruelo, D.; Manden, M. Br: J. Cancer 1999, 79, 423

7. Colasanti, A.; Kisslinger, A.; Liuzzi, R.; Quarto, M.; Riccio, P.; Roberti, G; Tramontano, D.; Villani, F. J. Photochem. Photobiol. B: Biol. 2000, 54, 103 .

8. Hoepfner, M.; Maaser, K.; Theiss, A.; Lenz, M.; Sutter, A. P.; Kashtan, H.; von Lampe, B.; Riecken, E. O.; Zeitz, M.; Scherueb], H. Int. J. Colorectul. Dis. 2003, 18, 239.

9. Kamuhabwa, A. A. R.; Cosserat-Geradin, I.; Didelon, J.; Notter, D.: Guillemin, F.; Roskams, T.; DHallewin, M.-A.; Baert, L.; de Witte, P. A. M. Int. J. Cancer 2002, 97, 253.

10. Chen, B.; Roskams, T.; de Witte, P. A. M. Lasers in Singerv and Medicine 2002, 31, 158 .

11. Takahashi, I.; Nakanishi, S.; Kobayashi, E.; Nakano, H.; Suzuki, K.; Tamaoki, T. Biochem. Biophs. Res. Commun. 1989, 165, 1207.

12. Couldwell, W. T.; LIhm, J. H.; Antel, J. P.; Yong, V. W. Nentrostgerv $1991,29,880$

13. Nishizuka, Y. JAMA. 1989, 262, 1826.

14. Tysnes, O. B.; Laerum, O. D. Anticancer Res. 1993, 13, 1325.

15. Baltuch, G. H.; Couldwell, W. T.; Villemure, J. G.; Yong, V. W. Yenosimgerv $1993,33,495$.

16. Couldwell, W. T.; Hinton, D. R.; He, S.; Chen, T. C.; Sebat, I.; Weiss, M. H.; Law, R. E. FEBS Lett. 1994, 345, 43.

17. Vanbilloen, H.; Bormans, G.; Chen, P.; de Witte, P. A. M.; Verbruggen, A.; Verbeke, K. I. Labelled Cpd. Radiophann. 2001, 44(Supp. 1), \$965.

18. Bormans, G; Huygye, D.; Christiaen, A.; Verbeke, K.; de Groot, T.; Vanvilloen, H.; de Witte, P. A. M.; Verbruggen, A. J. Labelled Cpd. Radiopharm. 2004, 47, 191 .

19. Brockmann, H.; Kluge, F.; Muxfeldt, H. Chem. Ber: 1957, 90, 2302.

20. Falk, H.; Schoppel, G Monatsh. Chen. 1992, 123, 931.

21. Kim, S. W.; Park, J. H; Yang, S. D.; Hur, M. G; Kim, Y.-S.; Chai, J.-S.; Kim, Y. S.; Yu, K. H. Bull. Korean Chem. Soc. 2004, 25, 1147.

22. Chen, B.; Roskams, T.; de Witte, P. A. M. Photochem. Photobiol. 2002, 76, 509

23. Daniel, C. Hippokrates 1949, 19, \$26.

24. Vandenbogaerde, A. L.; Delaey, E. M.; Vantieghem, A. M.; Himpens, B. E.; Merlevede, W. J.; de Witte, P. A. M. J. Photochent. Photobiol. B: Biol. 1998, 45,87.

25. Kamuhabwa, A. A. R.: Agostinis, P.: DHallewin, M.-A.; Kasran, A.; de Witte, P. A. M. Anticancer Res. 2000, 20, 2579 